\title{
A Tribute to Nutrio-Diabetologist; Shanti S. Rastogi MBBS, MD, FRCP, FICN, FICC
}

\author{
Ram B. Singh ${ }^{1, *}$, Amrat K. Singh ${ }^{2}$, Hideki Mori ${ }^{3}$, Daniel Pella ${ }^{4}$, Tapan K. Basu ${ }^{5}$, Lech Ozimek ${ }^{5}$, \\ Shailendra K. Vajpeyee ${ }^{6}$, Douglas W. Wilson ${ }^{7}$, Fabien De Meester ${ }^{8}$, Krasimira Hristova ${ }^{9}$, Lekh \\ Juneja $^{10}$, Sukhinder Kaur ${ }^{11}$, Manohar Garg ${ }^{12}$, Toru Takahashi ${ }^{13}$, Adarsh Kumar ${ }^{14}$, Rajiv Garg ${ }^{15}$, \\ Nirankar S. Neki ${ }^{16}$, R. G. Singh ${ }^{17}$ and Sharad Rastogi ${ }^{18}$
}

${ }^{1}$ Halberg Hospital and Research Institute, Moradabad, India, ${ }^{2}$ Neuron Hospital, Moradabad, India, ${ }^{3}$ Formerly, Amoari Prefectural Central Hospital, Japan, ${ }^{4}$ PJ Safaric University, Kosice, Slovakia, ${ }^{5}$ University of Alberta, Edmonton, Canada, ${ }^{6}$ Government Medical College, Surat, India, ${ }^{7}$ School of Medicine, Pharmacy and Health, Durham University, UK, ${ }^{8}$ The Tsim Tsoum Institute, Krakow, Poland, ${ }^{9}$ National Heart Hospital, Sofia, Bulgaria, ${ }^{10}$ Chief Health Officer CHO, Rohto Pharmaceutical Co. Ltd. Osaka, Japan, ${ }^{11}$ Faculty of Medicine, Memorial University of Newfoundland, St John's Canada, ${ }^{12}$ School of Biomedical Sciences and Pharmacy, University of Newcastle, Newcastle, Australia, ${ }^{13}$ Graduate School of Environmental Sciences, Fukuoka, Japan, ${ }^{14}$ Government Medical College, Amritsar, India, ${ }^{15}$ ESI Hospital, New Delhi (Executive Member, ICN), ${ }^{16}$ Government. Medical College, Amritsar, India, ${ }^{17}$ Institute of Medical Sciences, BHU, Varanasi, India, ${ }^{18}$ The Medical Affairs Company, Atlanta, GA, USA

Dr. Shanti Swarup Rastogi Fig. (1) who pioneered the Diet and Lifestyle guidelines of India was a staunch and steadfast friend who believed in the warmth of friendship. Dr. Rastogi gave his all love to those who were his friends and hence he was affectionately called Nawab Sahib. Once I (RBS) found him worried, because he was of the opinion that his son Dr. Sharad was not that liberal with his friends. He wanted him to be liberal and to be called at least Chhote Nawab by his friends. He was a shining light that guided us with his extraordinary enthusiasm and he would never say NO to anything. He was a visionary with 'nutriological ideas' and his work, ethos and energy were exemplary.

In the last three decades, Dr. Rastogi co-authored approximately 200 research papers including some important classical articles that have been published in world-class journals. He presented these views in national and international conferences such as those held in Canada, UK, Japan, USA, China, Taiwan, Indonesia, Thailand and in many other countries. We missed him in the $17^{\text {th }}$ World Congress on Clinical Nutrition, Sofia, Bulgaria in which he was unable to preside due to aplastic anemia from which he was suffering for the past year. I posed the question with him; "Can drug eluting stents cause this illness" because another doctor friend with similar stents also developed aplastic anemia. We also humourously posed another question, "Why did you stop making the platelets"; his answer was, "because it is platelets which caused thrombosis resulting in heart attack". Cardiologists asked him not to take aspirin to prevent stent thrombosis which he had about a year ago. The association of aplastic anemia with stents needs further studies.

*Address correspondence to this author at the Halberg Hospital and Research Institute, Civil Lines, Moradabad (UP)244001,India;

Tel/Fax: 00915912417437; Email: rbs@tsimtsoum.net
We in the International College of Nutrition and International College of Cardiology (of which he was a founder member), will always think of him as great friend and his parting a great loss. For members of these two organizations, worldwide, including Indian, Canadian and Slovakian friends, Dr. Rastogi remains an integral part of what we plan and what we do. After India, his next home was the whole world. He planned great adventures in India, Canada and UK for the first time and we should keep them alive. He was the first in India to bring nutritional science for clinical practice from laboratory to patient care by organizing the First World Congress on Clinical Nutrition, in Feb 1988 at Ashoka Hotel, New Delhi, under the banner of the International College of Nutrition. He was the first diabetologist in India in 1988, to advocate, fruits and nuts to patients with type 2 diabetes to supply antioxidants,



Fig. (1). Shanti S Rastogi (Oct 14, 1938-June 11, 2014). 
flavonoids and w-3 fatty acids to prevent vascular complications and insulin insensitivity in diabetes.

Dr. Rastogi advocated for all of us taking us a step beyond the noosphere by examining both the basic rules and their applications emphasizing the role of foods rather than nutrients in the prevention of non-communicable diseases in 1988. This functional food approach proposed by Dr. Rastogi was protective against type 2 diabetes as well as cardiovascular disease and brain degeneration. Dr. Rastogi acted like Charak and Hippocrates by this new approach. Hippocrates proposed "Let food be our Medicine" so did Dr. Rastogi "Let food be used to control diabetes". In classical Greek, "noos" and "nous" means the same, that is the human mind, the Attic Greek "nous" serves to portmanteau it into "chronos", time and "sphairos", sphere hence "chronousphere". Dr. Rastogi's stamina and enthusiasm support his inquiries and hypotheses; viz. Food-Mind-BrainBody connection via pineal-hypothalamic-pituitary-adrenalcellular network mediated by BDNF first, and cosmos next which he developed after his discussions with Prof Dr. Franz Halberg, the Father of Chronobiology from Minneapolis who left us last year. Dr. Rastogi's last contributions were assessment of data for examining the role of natural health products in modulating blood glucose and insulin resistance. He observed that the same amount of food can enhance or delay the rise in blood glucose depending upon the nutrient content. His leadership is apparent from recent guidelines about the prevention of diabetes and cardiovascular disease published in 2011 in the Open Nutraceutical Journal [1].

His group was the first in the world (1992) to demonstrate in a randomized, controlled trial, of patients with acute myocardial infarction, that fruits, vegetables, legumes and nuts can decrease blood glucose and blood lipids along with significant reduction in mortality within one-two year [2-4] (Figs. (2, 3), World Heart J 2012).
Simultaneously, he co-authored two more classic papers published in the American Journal of Cardiology including the Indian Diet Heart study [3,4]. These classic papers inspired the world nutrition research leading to publication of the Lyon heart Study by Serge Renaud of France in 1994 [5,6]. These papers were the first in the world to prove the validity of Mediterranean style diet and Seven Country Study in the prevention of cardiovascular diseases.

Dr. Rastogi was instrumental in developing the Indian Consensus Group in the 1990s, leading to publication of "Indian consensus for prevention of hypertension and coronary artery disease. A scientific statement of the Indian Society of Hypertension and International College of Nutrition" was published for the first time in Indian History of Medicine [7]. No other guidelines were available for Indians before this publication, apart from guidelines of the National Cholesterol Education Program including American Heart Association [8] and the World Health Organization [9]. This situation was the impetus for Dr. Rastogi to plan the Indo-Mediterranean Diet study, in which 1000 high-risk subjects were included to examine the effects of traditional Indian foods and Mediterranean-style foods for the prevention of cardiovascular diseases [10].

In a population survey among elderly populations he reported "Blood pressure trends, plasma insulin levels, and risk factors in rural and urban elderly populations of north India", for the first time in India [11]. These findings emphasized that insulin resistance varies in different populations of India due to differences in diet and lifestyle, rather than any possibility of a genetic basis. His group also conducted epidemiologic study of hypertension and its determinants in an urban population of north India [12] and clinical characteristics of hypertension among patients of noninsulin dependent diabetes mellitus in North and South India [13]. Dr. Rastogi was the first few investigators who

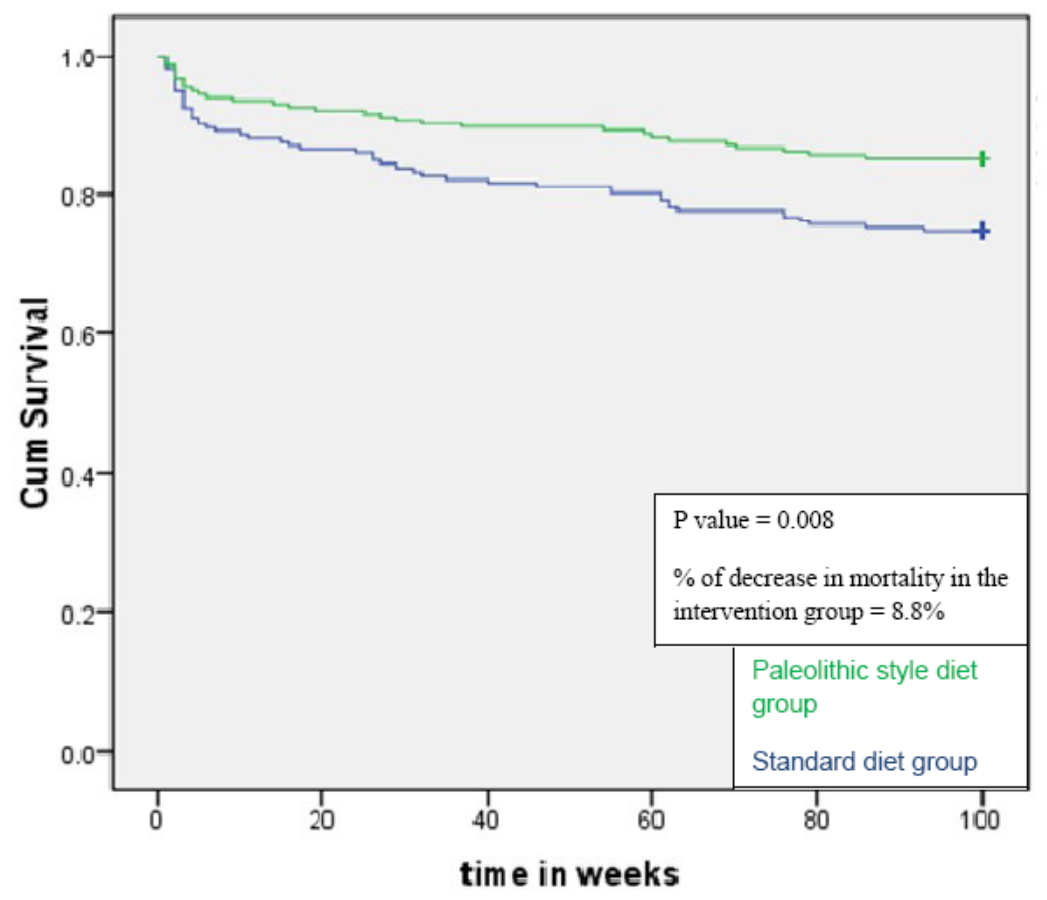

Fig. (2). Kaplan-Meier survival curves: proportions of deaths after 2 Years.(Singh et al, WHJ 2012;4:71-84). 


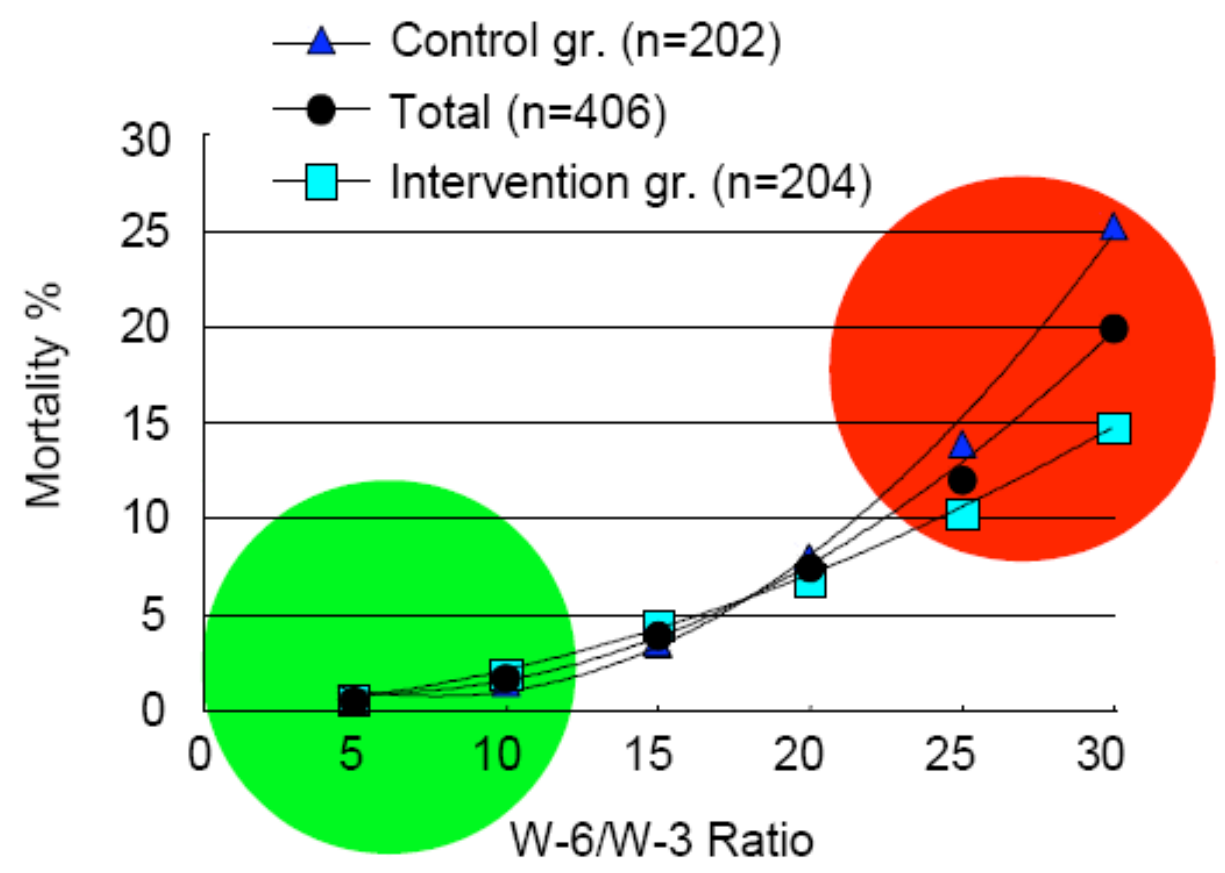

Fig. (3). Association of W-6/W-3 ratio of fatty acids with mortality in the intervention, control group and total number of subjects. (Singh et al., WHJ 2012;4:71-84.).

reported the prevalence of type 2 diabetes mellitus and risk of hypertension and coronary artery disease in rural and urban population with low rates of obesity, which is a paradox he observed in the UK in 1971 [14]. In this study, two populations of the same ethnic background were randomly selected for this cross sectional survey from rural and urban areas of North India [13]. There were 1769 rural (894 men, 875 women) and 1806 urban subjects (904 men, 902 women) between 25-64 years of age. The objective was to compare the prevalence of type 2 diabetes mellitus and coronary artery disease (CAD) and hypertension in diabetes mellitus in the rural and urban populations of north India. Using the criteria of World Health Organization, the prevalence of diabetes mellitus (6.0 vs $2.8 \%)$ hypertension (24.0 vs $17.0 \%)$ and CAD (9.0 vs. $3.2 \%)$ were significantly $(\mathrm{P}<0.001)$ higher in urban compared to rural subjects. Hypertension and CAD were significantly more frequent among subjects with diabetes compared to non-diabetes. The association of CAD and hypertension with diabetes was greater in urban than rural subjects. Excess body weight and obesity, central obesity, sedentary lifestyle, higher visible fat intake (>25 g/day), and social class 1-3 (higher and middle) were significantly associated with diabetes. Multivariate logistic regression analysis showed that after adjustment of age and sex, body mass index, central obesity, sedentary lifestyle and higher visible fat intake and alcohol intake in men were significant risk factors of diabetes among all the sub-groups. The study showed a high prevalence of diabetes in urban north Indian population compared to rural subjects in the same ethnic group. CAD and hypertension were significantly associated with diabetes more in urban than rural subjects. The findings suggest that higher body mass index, waist-hip ratio and visible fat intake and sedentary lifestyle were risk factors of diabetes.
These findings lead him to publish "Diet and lifestyle guidelines and desirable levels of risk factors for the prevention of diabetes and its vascular complications in Indians: a scientific statement of the International College of Nutrition" [15]. More recently he encouraged his group to develop new "Diet and lifestyle guidelines and desirable levels of risk factors for prevention of cardiovascular disease and diabetes among elderly subjects: A revised scientific statement of the International College of Cardiology and International College of Nutrition-2011" in the World Heart J, (Table 1) [16]. Dr. Rastogi also examined the role of antioxidant vitamins and coenzyme Q10 in cardiovascular diseases [17,18]. His publications and ideas assure him a lasting place in the World Medical Sciences and in health care through which he will continue to contribute in the time to come [19].

Dr. Rastogi, a world renowned endocrinologist and diabetologist was born in a town at Sirsee (District Moradabad). After achieving an MBBS in1960 and MD in 1965 from GSVM Medical College, Kanpur, India, Dr. Rastogi was a physician in the government hospitals, at New Delhi from 1965 to 1970 . He then decided to go for superspecialization in endocrinology and diabetes. He worked in England from 1970-76 in the Hammersmith Hospital, London, UK and was trained by a world renowned endocrinologist of UK. He did his MRCP during his stay in London. He was first to observe in 1971 that people of South Asian origin have abdominal obesity compared to British with same body mass index. He was member and fellow of the Association of Physicians of India, Diabetes Association of India, and Endocrinology Society of India. He was president of the Delhi chapter of all these associations as well as of Indian Society of Hypertension. He was president and executive director of the International College of 
Table 1. Dietary guidelines and desirable level of risk factors for Indians.

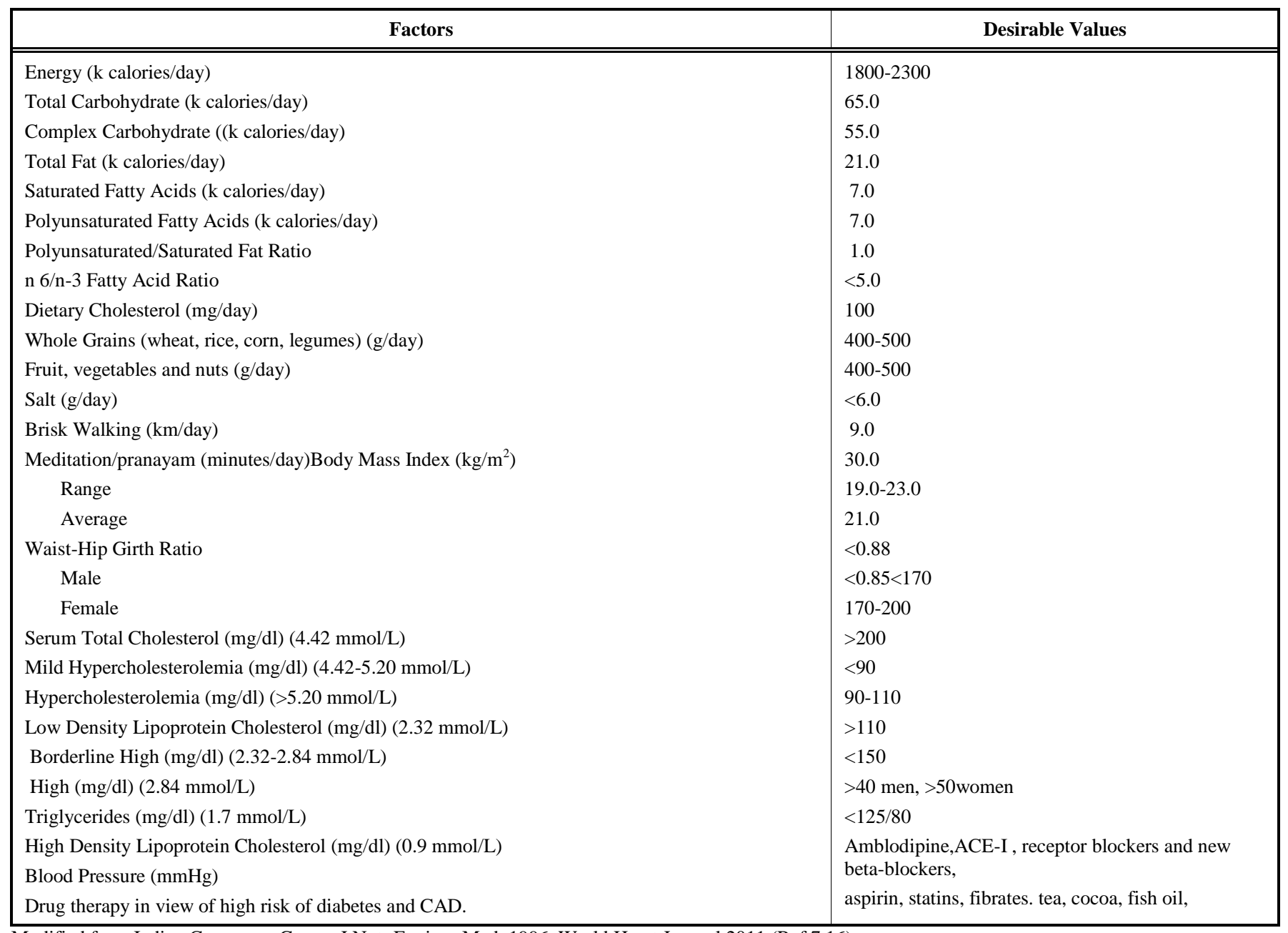

Modified from Indian Consensus Group, J Nutr Environ Med, 1996, World Heart Journal 2011 (Ref 7,16).

Nutrition and executive member of the International College of Cardiology. He is still listed as a member of the editorial board of the World Heart Journal.

We all are very sad to hear about the passing away of Dr. Rastogi. He was a noble soul, a very competent physician, and a compassionate teacher with excellent human skills. May God rest his soul in Peace in the chronousphere and give strength to the Family to bear this irreparable loss.

It is difficult to describe the sadness in such days but I will tell you that when we lose a loved one here on earth, we gain an angel in heaven that watches over us (L O, Canada). May we and Dr. Rastogi,s Family take comfort in knowing that we have an angel to watch over ALL of us now. Dr.. Rastogi is survived by his son Dr. Sharad S. Rastogi Daughter as well as wife.

\section{CONFLICT OF INTEREST}

The authors confirm that this article content has no conflict of interest.

\section{ACKNOWLEDGEMENTS}

None declared.

\section{REFERENCES}

[1] Rastogi SS, Singh RB, Singh NK, et al. Prevention of cardiovascular disease and diabetes mellitus in Low and Middle Income Countries. Open Nutraceuticals J 2011; 4: 97-106.

[2] Singh RB, Rastogi SS, Verma R, et al. Randomized, controlled trial of cardioprotective diet in patients with acute myocardial infarction : results of one year follow up. BMJ 1992; 304: 1015-9.

[3] Singh RB, Rastogi SS, Verma R, Bolaki L, Singh R, Ghosh S. An Indian experiment with nutritional modulation in acute myocardial infarction. Am J Cardiol 1992; 69: 879-85.

[4] Singh RB, Rastogi SS, Niaz MA, Ghosh S, Singh R. Effects of fat modified and fruits vegetable enriched diets on blood lipids in the Indian diet heart study. Am J Cardiol 1992, 69: 869-74.

[5] De Lorgeril M, Renaud S, Mamelle N, et al. Mediterranean alphalinolenic acid-rich diet in secondary prevention of coronary heart disease. Lancet 1994, 343(8911): 1454-9.

[6] De Lorgeril M, Salen P, Martin JL, Monjaud I, Delaye J, Mamelle N. Mediterranean diet, traditional risk factors and the rate of cardiovascular complications after myocardial infarction. Final report of the Lyon Diet Heart Study. Circulation 1999; 99: 779-85.

[7] Singh RB, Rastogi SS and Indian Consensus Group. Indian consensus for prevention of hypertension and coronary artery disease. A scientific statement of the Indian Society of Hypertension and International College of Nutrition. J Nutr Environ Med 1996; 6: 309-18.

[8] National Cholesterol Education Program; Report of the Expert Panel on detection, evaluation, and treatment of high blood cholesterol in adults. Arch Intern Med 1988; 148: 36-69. 
[9] World Health Organization. Diet, Nutrition and Prevention of Chronic Diseases. Geneva: WHO 1990.

[10] Singh RB, Dubnov G, Niaz MA, et al. Effect of an IndoMediterranean diet on progression of coronary disease in high risk patients: a randomized single blind trial. Lancet 2002; 360: 145561.

[11] Singh RB, Rastogi SS, Rastogi V, et al. Blood pressure trends, plasma insulin levels, and risk factors in rural and urban elderly populations of north India. Coron Artery Dis 1997; 8: 463-8.

[12] Singh RB, Beegum R, Ghosh S, et al. Epidemiologic study of hypertension and its determinants in an urban population of north India. J Hum Hypertens 1997; 11: 679-85.

[13] Singh RB, Beegom R, Rastogi V, Rastogi SS, Madhu V. Clinical characteristics of hypertension among patients of noninsulin dependent diabetes mellitus in North and South India. J Diab Assoc India 1996; 36: 45-50.

[14] Singh RB, Bajaj S, Niaz MAs, Rastogi SS, Moshiri M. Prevalence of type 2 diabetes mellitus and risk of hypertension and coronary artery disease in rural and urban population with low rates of obesity. Int J Cardiol 1998 ; 66(1): 65-72.

[15] Singh RB, Rastogi SS, Rao PV, et al. Diet and lifestyle guidelines and desirable levels of risk factors for the prevention of diabetes and its vascular complications in Indians: a scientific statement of the International College of Nutrition. J Cardiovasc Risk 1997; 4: 201-8.

[16] Singh RB, Kumar A, Neki NS, et al. Diet and lifestyle guidelines and desirable levels of risk factors for prevention of cardiovascular disease and diabetes among elderly subjects. A revised scientific statement of the International College of Cardiology and International College of Nutrition-2011. World Heart J 2011; 3: 303-20.

[17] Singh RB, Niaz MA, Rastogi SS, Rastogi S. Usefulness of antioxidant vitamins in suspected acute myocardial infarction. Am J Cardiol 1996; 77: 232-6.

[18] Singh RB, Niaz MA, Rastogi SS, Shukla PK, Thakur AS. Effect of hydrosoluble coenzyme Q10 on blood pressures and insulin resistance in hypertensive patients with coronary artery disease. J Hum Hypertens 1999; 13: 203-8.

[19] Hristova K, Ivy Shiue I, Pella D, et al. Sofia declaration on transition of prevention strategies for cardiovascular diseases and diabetes mellitus in developing countries: a statement from the international college of cardiology and international college of nutrition. Nutrition 2014; doi:10.1016/j.nut.2013.12.013.

\section{(C) Singh et al.; Licensee Bentham Open.}

This is an open access article licensed under the terms of the Creative Commons Attribution Non-Commercial License (http://creativecommons.org/licenses/ by-nc/3.0/) which permits unrestricted, non-commercial use, distribution and reproduction in any medium, provided the work is properly cited. 